Meta

Journal des traducteurs

Translators' Journal

\title{
Why the Grammars don't help very much
}

\section{Henry A. G. Gleason}

Volume 25, numéro 4, décembre 1980

URI : https://id.erudit.org/iderudit/002925ar

DOI : https://doi.org/10.7202/002925ar

Aller au sommaire du numéro

Éditeur(s)

Les Presses de l'Université de Montréal

ISSN

0026-0452 (imprimé)

1492-1421 (numérique)

Découvrir la revue

Citer cet article

Gleason, H. A. G. (1980). Why the Grammars don't help very much. Meta, 25(4), 409-420. https://doi.org/10.7202/002925ar d'utilisation que vous pouvez consulter en ligne.

https://apropos.erudit.org/fr/usagers/politique-dutilisation/ 


\title{
Why the Grammars don't help very much
}

\author{
Henry A. G. Gleason, JR.
}

The day of the convenient, mass-produced, electronic translating machine is upon us. You can buy, right off the shelf, a little hand-held device. Type in an English word and the French equivalent comes up on the display - or you can select various other pairs of languages. The promise is that very soon they will do more; they will pronounce the word as well.

The chief significance of this development for us - perhaps indeed, the only significance - is that these devices will reinforce the popular conviction that language learning and translation are merely matters of words. Take care of the words and everything else is trivial. You all know that folk-lore. Your appraisal of it is probably pretty much the same as mine. It needs no refuting here.

Or does it? Watch a translator at work and you may come to wonder. Other than paper and pencil or typewriter, the most conspicuous piece of equipment on his desk is a dictionary, or more likely an assortment of dictionaries. A large share of the translator's working time is devoted to pursuing words through their pages. Perhaps on a bookshelf nearby are some other reference works on the languages concerned, among them, a grammar. But the latter is very seldom consulted. A quick survey of a few professional translators turned up one who had a vague memory of using a grammar once, and nine who could remember nothing of the kind. Grammars are clearly dispensible. But without dictionaries, translation would grind to a halt. Translators are tied to word books. The naïve but astute observer sees their work as strongly wordoriented, not very different in actuality from the popular stereotype of translation.

I want to reflect on that situation. I do so as a linguist, not as a translator, as one whose involvement in translation has been largely on the sidelines, but one whose indirect involvement has been extensive and varied. As my title suggests, I want to focus on the question as to why translators do not find grammars helpful, why they make infrequent and usually ineffective use of them. But I must also examine the other side of the contrast: Why do translators find dictionaries so helpful, so indispensible?

We have, perhaps, taken the translator's use of dictionaries so long for granted that we do not see immediately why the latter question needs to be asked at all, say nothing of subjecting it to serious consideration. But the matter is, really, neither simple nor obvious. 
Translators are, typically, highly competent readers of both the languages with which they deal. Competent readers - even moderately competent readers - when they are reading, make very little use of dictionaries. It is not that they never run into unknown words, quite the contrary. Even the simplest material is likely to contain something new, and in some material new items are present in abundance. The reader does not turn to the dictionary for the meaning of each unfamiliar lexical item. Instead he processes them as he comes upon them in very much the same way that he processes the familar items. Most certainly the reader does not have two distinct strategies, one for known words - roughly, to retrieve a meaning from memory - and one for unknown words - roughly, to deduce a meaning from context. Indeed, there is no such dichotomy as known and unknown, but a gradient from better known to less well known. The gradient does extend at one end, rather rarety, to totally unknown, but not at the other end to the totally known.

Each lexical item is processed in much the same way. The reader deduces the meaning - so far as the meaning is needed and no further - from some combination of : 1) memory of past contacts with the same item, and including memory of other things besides meaning; 2) perceived relationship to other "known" words, that is, etymology, including popular etymology, and 3) context, both textual and situational. Totally new words differ from "known" words only in that the first factor is zero; there is no remembered data. But that is a small difference, after all, since remembered meaning is often fuzzy at best, very seldom carries the load alone, and quite often is really a very minor element. to the extent that reading is an operation with word meanings at all, effective reading is more a matter of determining word meanings than of knowing them.

But surely, some will say, such a statement is too sweeping; some core of very familiar words we must simply know; their meanings need only be recalled. But it is precisely these very common lexical items that most effectively make my point. Not one of them has a single meaning and a single use, or a single stylistic value, or a single connotation. To have such would be incompatible with being common - except in a world exclusively furnished with the most trivial sort of literature, or one where language is artificially non-human. The commonest items are polysemous; if not also homonymous. And, however we enumerate the senses, each spreads out over a wide range of uses, of nuance, of suggestiveness. All our knowledge can do in the best of instances is to provide a list of interpretations from which we can select an appropriate one. It can never tell us "the meaning". Indeed, to think of it as a list of discrete possibilities is totally fallacious. They intergrade and interconnect and interact in every conceivable way; and some are themselves vague and fluctuant.

So there remains a great deal to be determined about the meaning - any kind of meaning - of even the most familiar words. How this processing is actually done is little understood. But it is clear that the ability to do this is a major component of competence as a reader. A semantic theory that deals only with stored meanings and their retrieval is dangerously simplistic. There can 
be no discontinuity, in either theory or practice, between known and unknown lexical items.

Reading, an activity practiced by a large segment of the population more or less effectively, is only one kind of text processing. Translation and exegesis are two others. They are not so widely practiced, and casual practicioners are seldom effective. An immediately apparent difference is that dictionaries, when available, are widely and intensively used. There must be something fundamentally different behind this surface difference, and there is.

But first consider a rather phoney sort of "translation" which to an alarming extent, I suspect, sets the attitudes of the educated public to translation. I refer to a sort of exercise commonly used in language instruction. Sentences sometimes rather strange sentences - or short connected passages are set. The student is to produce a "translation". There are fairly mechanical rules about how to do this. Behind the exercise is the ever-present assumption that lexical items are either known or unknown. Known ones have been memorized, an item with a gloss, an item with a gloss, ...endlessly, mindlessly. Unknown ones are in the dictionary, an item with a gloss, an item with a gloss, ...page after page. "Translation" approximates substituting gloss for item, gloss for item,... down the line, and then minimal adjustment to the proprieties of the target language. If the input is often strange, the output is often stranger, epitomized, perhaps, by that famous classroom translation of the opening words of De Bello Gallico : "All Gaul is quartered into three halves."

There is, incidentally, another assumed dichotomy, between well-behaved words and "idioms" items that can't be translated word by word, but which must be treated as units, translated whole idiom by whole idiom. That dichotomy, too, is far too simple. It is not merely that intergrades can be found, but that items, word or idiom that behave as commonly assumed are rare indeed. The better school dictionaries list the commoner idioms just as they do words, idiom with gloss, idiom with gloss, and just as mindlessly. The rarer ones are given up on and explained in footnotes to the exercises.

Trained thus, the educated public knows what a bilingual dictionary is for: it is to find glosses for unknown words, and occasionally for unknown idioms. If inadvertantly you look up a known word, or a word you are supposed to know, you just hope the teacher doesn't find out about that. You are supposed to know certain words and to know that you know them, to recognize the ones you don't know as unknown, and to use your dictionary skills on them and on them only, and always on them. Never, never, let an unknown word slip by you without proper attention to it. Thus you learn the language. And if some approximation to native-like competence is your goal, well, learn all the words - the native speaker never uses a dictionary, does he? Ergo, he must know all the words.

If that is your model of translating, and of bilingual dictionary use, watch the skilled translator at work. He does in fact know a lot of words. He should need to use the dictionary only very occasionally. But he uses it cons- 
tantly. Most of the time he is not looking up unknown words, but known. Sometimes partially known (we must get away from that dichotomy of known and unknown), but sometimes very well known words, familiar old friends that he re-meets almost every day. Certainly neither the class-room translation exercise nor the typical reader offers a model on the basis of which we can understand such behaviour!

Now, consider the exegete. I shall speak specifically of the student of the Hebrew Scriptures, but much the same would be the case for any other comparable body of literature. The exegete may even go so far as to look up every word in his passage, some of them in more than one dictionary! The dictionary that he uses is crucially different from the typical school dictionary. For most words, Brown, Driver, and Briggs lists every occurrence, with precise reference and fragmentary citation; when it does not, the user is explicitly warned. The exegete concentrates his attention not on what the dictionary says about the meaning of the word, but on the citations. He may look at such a quotation, judge it of no relevance, and dismiss it; or he may turn to it in the text and examine it in its context; or the entry may simply refresh his memory - after all he is, ideally, well acquainted with the whole corpus and needs only to have his memory jogged. In any case, the exegete is much less interested in the lexicographers' conclusions - even a little distrustful of them - than he is in the evidence adduced, evidence that our exegete can himself use to bolster, or to test, his own conclusions. And in it all, note well, the dictionary is often. less a substitute for memory than a prod to memory.

Why all this chasing of innumerable leads from passage to dictionary and back to the text in some distant place, occasionally through a second or even a third loop? The reader seeks a reading that is good enough; the exegete the best obtainable. The reader is usually satisfied with the first reading that occurs to him; the exegete wants to find and weigh all available readings. For exegesis, the ordinary reader's competence will not serve. Normal reading is a conclusionjumping exercise. The reader grasps the first workable reading, and then can see no more. It may be right - it often is. But it may be a little less than right, or it may be totally wrong. The exegete must seek the readings that ordinary reading hides from the reader. He must, indeed, do some of what he does simply to combat his ordinary reading competence. He must never succomb to being an ordinary reader.

Years ago I heard a mountain preacher interpret the text: "marrying and giving in marriage", as referring to weddings and divorces. That is, in his dialect, though not perhaps yours, a fair enough reading for "give in", but it is not good exegesis. Subtler examples abound. Exegesis and reading can be in opposition; they are not the same process, and the one must be kept out of the other.

In a typical sort of translation the objective is to produce a text in the target language from which the ordinary reader will get essentially the same meaning, or meanings, as the ordinary reader gets from the source document. But we are dealing with two languages that are, in finer details, at least, incommensura- 
ble. Their texts do not suggest meanings to their competent readers in the same way. There may be similarities - for French and English very many of them, for some other pairs very many fewer - but we can never rest content with such similarities. An accompanying small difference can upset the equivalence in a disasterous way. The parts of a text, you remember, interact intricately. So no easily translatable fragment is immune to influence from some nearby more problematic piece.

The translator needs a much more precise assessment of the meaning of a text than does the reader. His work on the source text must be much more nearly like that of the exegete. This is because he must be constantly balancing in his mind two systems, and always aware of the finest nuances in each. Not subconsciously aware, as suffices for the reader, but in full and deliberate awareness. And like the exegete, he must guard against conclusion-jumping; he must never allow his simple reading competence to take over, but must subject it continuously to check.

If that is the case, the translator would like a dictionary more like the exegete's than like the student's. And he does. Indeed, translators I have known and watched have built extensive lexical files supplemental to the dictionaries they are using, even when that has been of the high standard of the Thesaurus Linguae Latinae. These files have contained just the sort of material the exegete would want, mostly citations of actual use, and all sorts of notations not so much on "meanings" naïvely considered, as on the ways words are used, their collocations, their stylistic implications, their connotations, their allusionary suggestiveness, and the like - and above all actual citations in abundance.

I do not wish this discussion of the lexicographic demands of translators, or of their dictionary use, to become a consuming digression. Rather I wish to use it as a base from which to examine the rather similar problem of the translator's processing of the grammatical patterns. So I must leave it with a reiteration of two principles: The use of dictionaries is symptomatic of a profound difference between reading and translating. Dictionaries are not used primarily to find meanings of unknown words, but among other things to enable the translator to guard against becoming a mere reader.

A text is a series of words and at the same time a nesting of grammatical patterns. In our word-oriented thinking, the patterns are little more than the arrangement of the words. Practically they are minor guides in combining word meanings to get sentence meanings. In most cases they seem to require little direct attention on their own, and in many instances they can, we seem to feel, be safely overlooked.

But if we look at anything other than the simplest examples we find that the grammatical patterns contribute to the meaning in more subtle ways. Consider for example a pair of sentences such as the following

John walked.

John took a walk.

At some very gross level these two mean the same. At this level the same translation might serve for both in French, or indeed, in almost any language. 
But at any other than this very gross level the two have some very distinct flavour and this distinction deserves to be reflected, somehow in a translation. If, now, we try to localize the difference in the sentences, two possibilities leap immediately to mind: The difference rests in the presence or absense of the verb take, or in the verbness or nounness of walk. The more you reflect on either the greater the difficulties, particularly if you bring in parallels :

\section{Kenneth examined the note closely. \\ Kenneth gave the note a close examination. \\ Leslie rested for ten minutes. \\ Leslie had a ten-minute rest.}

These, and the language abounds in their likes, suggest to me that the difference lies, not in any lexical dimension, but in the difference in clause pattern, in the options open in English to express the involvement of a participant (or two) with an action. The meaning is carried both by lexical elements and their grammatical patterns.

If this is so, then the reader processes not only words, but also patterns. There is in my mind no doubt but that patterns, like words, vary in their familiarity. A good number come so close to one extreme that we can count them as known, but they trail off, through the barely familiar to the unknown. That is the case, at least, if we ask merely about the identities of the patterns. But like the most familiar words, the most familiar patterns have broad ranges of meanings and use. If we were to pile up examples like the three pairs of English sentences I just gave, we would see this clearly. The rhetorical usefulness, the stylistic nuance, the secondary semantic implications, or whatever dimensions we can discriminate - all these vary subtly from example to example, not wildly or randomly, but in much the same way that the values of a word range over a segment of semantic or stylistic space.

The competent reader takes all this in stride, just as he does the comparable complexity in the lexical resources. I see no alternative but to postulate of the grammatical patterns what I have already claimed of the vocabulary items. The competent reader processes them, more familiar or less familiar, in much the same way. If anything, he is less aware when he comes upon a poorly known grammatical pattern than when he comes on a poorly known word. The most naive is at least aware that the words exist and that they can present problems - too aware perhaps - but he may be completely unaware of the patterns, rare or common. One consequence of this difference in awareness is this: If he finds a passage unreadable - and most of us do from time to time - it is always the vocabulary that is blamed. Witness, if you will, the footnotes provided to help beginning students through Shakespeare's plays.The difficulties are overwhelmingly judged by the editors to be lexical. My experience is that they are at least as often grammatical.

But is it fair to use a student reading Shakespeare as a paradigm? I believe it is. Once he has gotten something of a start so that he reads with reasonable fluency, he becomes less and less aware of the strangeness of the language. But he does not cease running into grammatical patterns that are new to him, or 
at least very imperfectly known. Most of these he does not notice, but processes just as he would somewhat more familiar patterns, using a variety of clues, contextual, lexical, and percieved similarities or contrasts with better known patterns. Many students emerge able to read Shakespeare; some to read for unfeigned enjoyment. But few can really handle Shakespeare at a critical level, that is, a close critical level, even among graduate students in English. They misinterpret grammatical patterns - misinterpretations that do not matter at the ordinary reader's level, but may be serious for the critic or the translator.

Shakespeare is a paradigm, not a unique case. Less familiar and unfamiliar patterns abound in everything other than the most carefully structure-controlled reading materials. Even the first-grade reader may have them. Run, Spot, run. is not wholly familiar. Some beginners will be tripped up; some will take it in stride. After all they have been processing unfamiliar grammatical patterns assiduously for at least four years, building many, but not all of them into their growing repertoire of familiar ones. Language learning is the one thing at which six-year olds are real experts, and language learning comes from processing new linguistic items, words and patterns.

Little as we know about how the reader (or hearer) processes vocabulary, we know even less about how the processing of structure is done. You can, if you choose, dismiss as a mere guess my contention that the two are parallel in important ways. My evidence is scant and unchecked, largely anecdotal. But if you will grant me the reasonableness of my guess, then some significant suggestions follow. Grammatical processing seems likely to be much the same sort of conclusion-jumping operation. We seize on the first fairly acceptable interpretation and then close off further examination.

And if this is so, we should need, for exegesis or translation, some technique to keep our options open through a more extended examination. Since lexical meaning and grammatical meaning interact, the translator's use of the dictionary does occasionally reopen a grammatical question, and so does partially serve. But only partially. That same interacting should work in the opposite way as well. Thorough pursuing of the details of patterns and their values should provide leads toward the solution of lexical problems, and hints that will reopen ones prematurely closed.

I wish to suggest, in short, that translational efficiency and effectiveness would be advanced by the same meticulous consideration of grammatical patterns that is standard with lexical items. By that I mean, first specific attention to patterns, and second frequent searching beyond immediately apprehended meaning or translational possibilities - a vigorous effort to keep crucial questions open until they have been more thoroughly explored than they customarily are by the competent reader.

Let me illustrate part of what I have in mind by a simple example.

The man gave the house a coat of paint. We wish to translate into German. Operating in a more or less word-centred way, we start out with fairly obvious equivalents, giving no more concern to grammar than the rather simple matters of gender and the use of dative for an indirect object : 


\section{Der Man gab dem Haus.}

But at about the time we search our mind or the lexicon for an equivalent for coat of paint, we realize that this translation isn't going to work. But, anyway, we will have assembled the pieces, more or less, and what remains is to juggle them a bit until we get acceptable German. From this starting point, however, everything is conspiring against our coming up with effective German; patching up a misfit is not the best route, but a good translator can overcome the handicap. Now consider an alternative procedure :

We observe, first, that the English sentence at hand is a special case of the sort of thing I illustrated earlier. Gave is here the empty verb required when a transitive action is put into the direct object, and the indirect object here expresses not recipient but patient. The sentence is related to

The man painted the house.

What has happened to coat? Well, that seems to be an item of minimal lexical content, much like gave, more a grammatical feature than anything else. It is, therefore, the sort of item that can be very freely treated in translation. Now, The man painted the house, can be rather easily translated into many languages, and its translation will serve, at one level, as a translation of the sentence under consideration.

But, of course, there is a difference between the two sentences in English, a difference perhaps of style, perhaps of rhetorical strategy. So now what we should do is to consider the various options available in German to express the agent-patient-transitive-action sort of proposition and ask, is any other than the subject-verb-direct-object construction more appropriate in this context, stylistically or strategically appropriate?

Or should we strive for the proper effect by some other device?

I do not want to suggest that any translator would proceed exactly as I have outlined. Those descriptions were intended to be schematic, to throw into maximum relief two approaches, one avoiding grammar as long as possible, the other siezing on a grammatical point of attack and exploiting it fully.

Two immediate observations: If a translator were to take the second approach, just how far he would seek after a stylistic and rhetorical equivalent would depend on the level of translation demanded. For some purposes, the simple "kernel" translation is sufficient. For this kind of translation, too, the translator would certainly search less dilligently through his dictionary. The simplest most obvious lexical equivalents will do also. But for a higher quality translation, the grammatical options will have to be pondered rather thoroughly, and the choice made with care and full consideration.

To make those grammatical choices with full attention to all the variables involved will require access to some considerable body of grammatical lore about the target language. To see the problem as I have presented it will require some considerable store of grammatical information about the source language. To avoid conclusion-jumping, that material will have to be external to the trans- 
Yator, in a position to act as a check - as a good dictionary does - on his normal language behaviour. That would seem to indicate regular use of grammars alongside the dictionaries.

The facts of current practice are, as we all know, quite the contrary. Grammatical considerations are not wholly neglected, but grammars are not used; they are not even considered as a serious possibility. So, at long last, I have now posed the question as I should like to pose it - the question to which this paper is addressed : Why don't the grammars help very much ?

Granted my understanding of the problem, the answer could lie in either or both of two places: with the grammars themselves, or with the translators.

Let me advert again to the exegete working with the Hebrew Scriptures. $\mathrm{He}$ is very likely to have at hand not merely a couple of dictionaries, but also Gesenius' Hebrâische Grammatik, or one of its derivatives. He uses that alongside his dictionaries in a very similar, parallel way. Most often he recognizes the grammatical construction, so he knows where to look. He doesn't merely read what Gesenius has to say about it. More particularly, he looks critically at the examples. Some are familiar; the grammar merely jogs his memory. Some look interesting, and he goes to their place in the text and looks at them closely in context. Some he judges not particularly relevant, and he does nothing more with them. As with the dictionary, it is the cited examples that are primarily sought in the grammar.

It is easy enough to find fault with Gesenius, and most users do. $\mathrm{He}$ is seriously wrong at some crucial points. They use his work, nevertheless. The curious conclusions can be overlooked, taken as mere arbitrary heads under which the evidence is gathered. And there they are, the parallels that the exegete needs. There are, however, crucial questions on which Gesenius says nothing at all. The questions had not been asked in his day, and he was unaware that anything could be said. Many present-day exegetes are just as unaware of the whole realm of supra-sentence grammar and so do not miss it. Here they flounder, relying only on their experience reading Hebrew, condemned to looking at the text as little more than mere readers - just as the typical translator is condemned in grammatical matters to being little more than a mere reader, though perhaps an extraordinarily skilled one.

The modern linguist looks on a grammar like Gesenius with a mixture of amusement, condescension, revulsion, and disbelief. Its theoretic undergirdings are weak, by the most charitable judgement. It gives only the haziest view of any broad picture - well, perhaps a little more than the average linguist can discern in it, but still not very much. It is loaded down with trivia. Far too much space is devoted to listing exceptions.

We might go into details comparing a grammar like Gesenius with a modern grammar. But it is much more to the point to compare the grammarians.

Gesenius was a philologist, not a linguist. The linguist-grammarian is far better at analyzing a language system and sketching out how it works and how the parts fit together. The philologist-grammarian is too busy recording 
the trees to see the forest. But the philologist-grammarian knows his market as the linguist-grammarian does not. He knows that a text is composed of trees the forest is mere background. The exegete wants the trivia, and he wants them documented, and he wants to be able to find them when he needs them. Gesenius gives them to him, documented, cross-referenced, foot-noted, meticulously indexed, in a familiar outline and terminology.

We cannot count Gesenius as an adequate grammar for either the exegete or the translator, or a model for one. But it does - particularly in contrast with more "linguistic" grammars - point toward what is needed. I would mention five points, four of them exemplified, however poorly, in Gesenius :

First, it gives copious examples. The modern linguist has come to think of examples, literary ones in particular, as something of a luxury. Constructed ones are preferred, since they usually fit the rule better, and are less obscured by other accompanying phenomena. Besides, the popular folk-lore has it that Bloomfieldian grammars "merely reshuffled the data"; Heaven forbid that any post-Bloomfieldian should include in a grammar anything that looked like data! A grammar to be useful for translators must give copious examples, carefully selected, wisely arranged, and with appropriate documentation.

Second, it does not practice apartheid, segregating less interesting patterns from more interesting, or even keeping the former discretely out of sight. Exceptions are anathema to the linguist; even, "unexplained residues" call to question his competence as a systematizer. But they crop up in texts presented to translators; they figure in conveying the message, and even more in creating a flavour. They can be neglected only at peril, and they have the same rights of recognition as any other of the languages resources. A grammar to be useful to translators must catalogue, whether they can be explained or not, all the patterns to its effective level of delicacy.

Third, it must be accessible. Two decades ago, US government grants financed a number of so-called "reference grammars" of "neglected languages". I was appalled by how many of them were published without an index of any sort, without a detailed table of contents, and with no cross referencing. They simply could not be used for reference - or for any other purpose except those of the theoretically-oriented linguist. A grammar to be useful for translators must be equipped with carefully designed, meticulously constructed, and widely varied lines of access.

Fourth, it must be modular. Many of those same grammars could not have served a reference purpose even if the place had been found. To get any answer you would have to read the whole, or a major section of it. A grammar to be useful to translators must be so constructed that, once the place is found, some reasonable (and demarkated) portion can be read. And these portions must be sufficiently self-contained that a user with reasonable background can get some answer without too often having to follow leads hither and you.

Fifth, it must discuss the semantic, stylistic, rhetorical, and connotational potentials of the patterns described. Since Katz and Postal, the mainline of North 
American linguistics has been concerned with semantics, but only with a mechanical componential sort of semantics that is far from adequate even for the most simple-minded sort of translation. Style, for example, is dismissed as a matter of performance, beyond the pale and not amenable to significant description. Rhetorical strategies, of course, can not be recognized within single sentences, and so are non-issues. A grammar to be useful for translation must give the best available information on the communicative function of the patterns described.

Such grammars we do not have, though there are some pale shadowings, like Gesenius. Quirk, Greenbaum, Lynch, and Svartvik, Grammar of Contemporary English is an example. It was not designed specifically for translators, but it does do some of the necessary things. It is not ideal, but it could be helpful. The authors, incidentally are philologist-grammarians, or perhaps early examples of what we need, philologist-linguist-grammarians. And some other languages, also, are similarly equipped.

In the meantime, though, translators do not make use of what there is. This is largely, of course, because they are unaware of the available resources, and because they are unaware of their grammatical problems - or rather, unaware of the subtlety of their grammatical problems. We are all of us affected, more than our intellectual credentials ought to suggest, by ambient folk-lore: Not only sophisticated versions of the vocabulary view of language. Just as much the conviction that grammar is simple, a set of constraints about verbs agreeing with subjects, and that prepositions are bad things for sentences to end with. These simple matters cause the skilled translator little difficulty - what then can a grammar contribute?

The only corrective to such a view that has been widely marketed in recent years is a view that has grammar deal with the ideal competence of ideal speakers divorced from any of the things that make texts interesting. Indeed, a linguistics that is not concerned with texts at all. And, moreover, a linguistics that becomes ever more concerned with broad abstractions of a universal nature as against the individuality of languages, of styles, of authors, or of documents. We need more of a philologic approach to grammar than an approach from that sort of linguistics. Alton Becker put the difference well : "Linguists are people who swoop down on East Java where you've been trying to understand a language for ten years, and steal a relative clause to use to prove a methodology. Philologists are the ones who complain about that" $(1980: 111)$.

But whatever may be the lesson for linguists - and there is certainly a major one for any linguist who is beginning to ask about his place in society the lesson for the translator is to me clear. The translator, if he is to move toward more efficent and effective translation, must give increasing attention to grammatical matters, and to the one best source of relevant help, the grammars, poor as they are. Maybe, as translators begin to use grammars more, they will create a demand for better, to which grammarians, happily combining philologic and linguistic skills, will respond. If we start that progression, things may happen rather rapidly both to translators and grammars. The science and 
craft of translation will advance, and, I hope, my paper and especially its title, "Why grammars don't help very much" will soon be obsolete.

\section{REFERENCE}

BECKER, A. L. A few personal remarks on Tagmemics (and on Linds Jones' paper), in Kac, Michael [ed.], Current Syntactic Theories: Discussion papers from the 1979. Milwaukee Syntax Conference, Indiana University Linguistics Club, 1980, p. 109-111. 